\title{
A Novel Algorithm-based MPPT Strategy for PV Power Systems under Partial Shading Conditions
}

\author{
Chian-Song Chiu ${ }^{1}, \mathrm{Sy} \mathrm{Ngo}^{1,2, *}$ \\ ${ }^{1}$ Department of Electrical Engineering, Chung Yuan Christian University, \\ Taoyuan City, Taiwan 32023, R.O.C \\ ${ }^{2}$ Institute of Engineering and Technology, Thu Dau Mot University, \\ Binh Duong, Vietnam \\ syn@tdmu.edu.vn
}

\begin{abstract}
This paper proposes a new simple method based on the simulation of a short-distance running race in athletics to track the maximum power point (MPP) for photovoltaic (PV) power systems, which can improve the tracking speed and search accuracy. In detail, the DC-DC boost converter is utilized to transfer the power of $P V$ panels to a load and follows the MPP all the time, regardless of the environmental temperature and variant solar irradiance. In the MPP search method based on the proposed short-distance running algorithm (SDRA), an appropriate duty ratio value will be found so that the load receives the highest electrical power from the PV energy system. As a result, the SDRA method has excellent MPP tracking ability with high convergence speed and no oscillation. The efficiency of the proposed method is verified by simulation and experiments. The proposed SDRA method overcomes the obstruction of local traps to achieve global MPP. The results have shown that the SDRA method has advantages in terms of better convergence speed and performance than the particle swarm optimization (PSO) and grey wolf algorithm (GWA) methods when they are operated under the same conditions.
\end{abstract}

Index Terms-DC-DC boost converter; Short-distance running algorithm (SDRA); Partial shading conditions; MPP tracking; Photovoltaic (PV) power.

\section{INTRODUCTION}

The efficiency of a photovoltaic (PV) power system is affected by two key factors: weather conditions and solar illuminance intensity. The plane of the PV panels that is in the perpendicular direction to the solar radiation will receive the best solar illuminance [1]. The sun changes position continuously over time, so controlling a PV system to receive the best energy is an extremely difficult task, increasing costs in installation and operation. In addition, weather conditions also affect the intensity of illuminance on PV panels; especially clouds will reduce the intensity of solar radiation and generate various intensity distributions on $\mathrm{PV}$ panels in which the power-voltage $(\mathrm{P}-\mathrm{V})$ curve

Manuscript received 6 December, 2021; accepted 16 February, 2022.

This work was supported by the Ministry of Science and Technology, R.O.C., under Grant No. MOST-107-2221-E-033- 064. exhibits only one global maximum power point (MPP) and multiple local maximum power peaks [2]. Without a viable solution, the PV system will operate at these local peaks. At that time, the power conversion efficiency of the PV system will decrease and cause energy waste.

To obtain higher performance, MPP tracking methods have also attracted growing attention from researchers. Conventional MPP tracking methods, such as the perturbation and observation (P\&O) method [3], the incremental conductance (IC) algorithm [4], the hill climbing (HC) technique [5], etc., are very effective in detecting MPP under uniform illuminance conditions. These MPP tracking algorithms show good accuracy and fast converging speed under uniform illuminance, in which the IC and P\&O methods are most commonly used to track MPP because they are simple, easy to program, and low cost [6]. However, when a PV system with multiple PV panels connected together to generate higher power, partial shading by trees, clouds, or buildings will produce different illuminance intensities on each PV panel, i.e., many local power peaks and only one global maximum power peak are generated. This implies that the above mentioned conventional methods easily fall into the local maxima traps with any local maximum power peak, i.e., failing to achieve the available global MPP. Thus, the improved methods exhibit great efforts to obtain the global value, such as using improved IC algorithm [7] or improved P\&O method [8].

To effectively solve the problems of partial shading influences, MPP searching based on artificial intelligence algorithms and meta-heuristic methods has attracted great attention from the research community. Indisputably, artificial intelligence methods have successively dealt with partial shading effects, as well as variations in ambient temperature, on PV panels [9]. Although these methods have shown encouraging results, artificial intelligence-based MPP tracking methods not only require massive training and computing time, but also require a large amount of data to train (i.e., require a large memory size) [10].

On the contrary, meta-heuristic methods have major advantages in terms of computational simplicity and do not 
require in-depth knowledge for the highly effective and accurate MPP tracking process under uniform and nonuniform illuminance effects and variant weather conditions on PV panels [11]. Some notable meta-heuristic methods are listed below: ant colony optimization (ACO) [12], bat algorithm (BA), firefly algorithm (FA) [13], cuckoo search (CS), flower pollination algorithm (FPA), grey wolf algorithm (GWA) [14], particle swarm optimization (PSO) [15], etc. In detail, the ACO, FPA methods are not only very efficient in terms of convergence time, but also achieve high efficiency and reliability even when dealing with rapidly changing weather conditions. A novel MPP tracking based on PSO for PV systems is presented in [16], so that the convergence time of the methods has been significantly reduced. Although the improved PSO can track time-variant global MPP, it still has undesirable steady-state oscillations around this global MPP. The GWA method and the shuffled frog leap algorithm (SFLA) method can efficiently find the global MPP with greater accuracy and less computation time than other methods, as stated in [17] and [18]. The BA [19] and CS [20] have been issued with better demonstrations by numerical simulation and experimental results. However, these methods are still quite complex. In addition, hybrid methods are also proposed to improve the search time and the search efficiency of global MPP [21]. The results are more robust and exhibit faster convergence, but the overall solution is still complicated and there are many arithmetic calculations [22].

After a thorough literature survey, based on the merits and demerits of the above mentioned methods, a new method is introduced in this article named the "shortdistance running algorithm" (SDRA). A typical structure of a stand-alone PV power conversion system [23] is considered to perform the evaluation of the proposed method. This system includes PV panels, the DC-DC boost converter, the MPP tracking controller, the pulse width modulation (PWM) controller, and a DC load as shown in Fig. 1. Inspired by observations of famous short-distance running races, the proposed SDRA method has marvelous tracking ability with the advantages in terms of high accuracy and zero oscillation amplitude. It exhibits good adaptability when dealing with rapidly changing weather situations and varying illuminance intensity disturbances on PV panels under partial shading conditions.

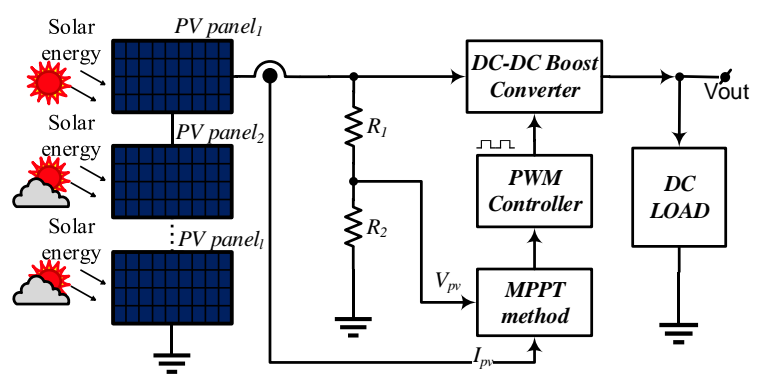

Fig. 1. Basic configuration for the stand-alone PV system.

The rest of the paper is organized in the following procedure. In Section II, the characteristic of the PV energy system is introduced, the equivalent circuit model of the PV array is given, the reasons for many peaks on the P-V curve are analyzed, and the key advantages of using the DC-DC boost converter are also presented. In Section III, the standalone PV energy system is described, while the MPP tracking control based on the new SDRA algorithm for PV energy systems is detailed. The MPP tracking simulation results are shown in Section IV. Section V slideshows the experimental results of the proposed method and other related methods. Finally, Section VI expresses some conclusions.

\section{CHARACTERISTIC OF PV ENERGY SYSTEM}

\section{A. Mathematical Model of the PV Array}

PV array is composed of several PV cells. A PV cell can be represented by an equivalent diode model as shown in [23]. The output current of the PV cell is represented by the mathematical equation as follows

$$
i_{\text {cell }}=I_{p h}-I_{D}-I_{p}=I_{p h}-I_{D}-\left(v_{\text {cell }}+i_{c e l l} R_{s}\right) / R_{p},
$$

where $i_{\text {cell }}$ and $v_{\text {cell }}$ are the output current and voltage of the PV cell, respectively; $I_{p h}$ is the current source generated from the PV cell, which is affected by solar irradiation according to

$$
I_{p h}=\left[I_{s c}+K_{s c}\left(T-T_{r e f}\right)\right] \lambda / 100,
$$

with $I_{D}$ is the current through the diode defined below

$$
I_{D}=I_{s a t}\left(e^{k_{o}\left(\mathrm{v}_{p v}+i_{p v} R_{s}\right)}-1\right),
$$

where $I_{\text {sat }}$ is the reverse saturation current. This current $I_{\text {sat }}$ is calculated as follows

$$
I_{s a t}=\left(T / T_{r e f}\right)^{3} I_{r s} e^{k_{o} E_{g p}\left(T / T_{r e f}-1\right)},
$$

in which all the symbols in the above equations are described in Table I.

TABLE I. SYMBOLS AND DESCRIPTION FOR PV CELL.

\begin{tabular}{|c|c|c|c|}
\hline Symbol & Description & Symbol & Description \\
\hline$R_{s}$ & Series resistance & $T$ & Operating temperature \\
\hline$R_{p}$ & Shunt resistance & $T_{r e f}$ & Reference temperature \\
\hline$I_{p h}$ & Photocurrent & $k_{o}$ & $k_{o}=A_{s} / k T B_{s}$ \\
\hline$E_{g p}$ & $E_{g p}=1.11 e v$ & $I_{s c}$ & Short-circuit current \\
\hline$A_{s}$ & $\begin{array}{c}\text { Electronic charge } \\
\left(1.6 \times 10^{-19} c\right)\end{array}$ & $k$ & $\begin{array}{c}\text { Boltzmann constant } \\
1.38 \times 10^{-23}(J / K)\end{array}$ \\
\hline$I_{r s}$ & $\begin{array}{c}\text { Reverse saturation } \\
\text { current }\end{array}$ & $B_{s}$ & $\begin{array}{c}\text { Ideal P-N junction } \\
\text { factor }\end{array}$ \\
\hline$N_{s}$ & $\begin{array}{c}\text { Number of serial } \\
\text { panels }\end{array}$ & $N_{p}$ & $\begin{array}{c}\text { Number of parallel } \\
\text { panels }\end{array}$ \\
\hline$i_{p v}$ & $\begin{array}{c}\text { Current of a PV } \\
\text { cell }\end{array}$ & $\lambda$ & Illuminance intensity \\
\hline$v_{p v}$ & $\begin{array}{c}\text { Voltage of a PV } \\
\text { cell }\end{array}$ & $K_{s c}$ & $\begin{array}{c}\text { Short-circuit current } \\
\text { coefficient }\end{array}$ \\
\hline
\end{tabular}

Since the current and voltage of one solar cell are limited, solar cells are connected in parallel and in series as a PV array to obtain the appropriate voltage and power. The equivalent model of the PV energy array is depicted as shown in Fig. 2. For simplicity in calculations, the effect of 
resistors $R_{s}, R_{p}$ is ignored. The characteristic nonlinear $V-I$ (voltage-current) equation of the PV array is expressed in the following form:

$$
\begin{gathered}
I_{p v}=N_{p}\left[I_{p h}-I_{s a t}\left(e^{k_{o} V_{p v} / N_{s}}-1\right)\right], \\
P_{p v}=V_{p v} I_{p v}=V_{p v} N_{p}\left[I_{p h}-I_{s a t}\left(e^{k_{o} V_{p v} / N_{s}}-1\right)\right] .
\end{gathered}
$$

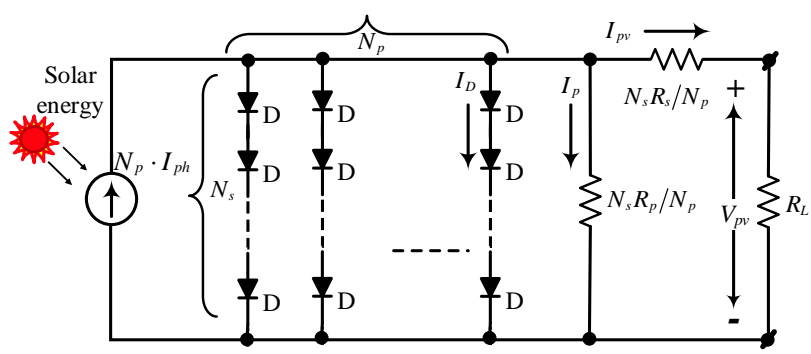

Fig. 2. Equivalent model of a PV array.

\section{B. P-V Characteristic under Partial Shading Influences}

The P-V curves of a PV array are influenced by the levels of solar irradiation intensity and the environmental temperature on the PV panels. When a PV power system is connected with serial PV panels, uniform solar irradiance on PV panels results in only one specific scenario affecting the output PV power. However, shadows of trees, buildings, and clouds will cause the partial shading on PV panels. To avoid the worst scenario, one diode is connected in parallel with each PV panel, as seen in Fig. 3. In this figure, the PV system composed of two serial PV panels is illuminated with two different scenarios. When all PV panels have the same intensity, the currents of PV panels are the same. If a PV panel is affected by partial shading, the output voltage and current of the shaded PV power panel will decrease. In the worst case, the output current of the shaded PV panel drops to the threshold, and the diode mentioned above will turn on. In other words, the main function of the diode is to conduct the current of the PV system and bypass the shaded PV panel to prevent the output current from dropping to the minimum value of this shaded PV panel.

For example, the two serial PV panels in partial shading case as shown in Fig. 3 (from top to bottom) are irradiated with intensities of $86 \mathrm{~mW} / \mathrm{cm}^{2}$ and $57 \mathrm{~mW} / \mathrm{cm}^{2}$, respectively, and $I_{1}, I_{2}$ are denoted as short-circuit currents for the two solar irradiation intensities, respectively (i.e., $I_{1}>I_{2}$ ). When the output current $I_{p v}$ of the PV system is less than $I_{2} \quad\left(I_{p v}<I_{2}\right)$, the diode $D_{1}$ and diode $D_{2}$ are reverse biased. These two PV power panels can supply a current limited by minimum irradiation intensity at the same time, and $V_{p v}=v_{p v 1}+v_{p v 2}$ is the total output voltage value of the PV system. When the output current $I_{p v}$ of the PV system falls into the case of $I_{2}<I_{p v}<I_{1}$, the diode $D_{2}$ is forward biased and conducts the current of the PV system, and the second PV panel is isolated, i.e., $I_{p v}=i_{p v 1}, i_{p v 2}=0$, and $V_{p v}=v_{p v 1}$. In other words, the output PV panel voltage is related to its output PV panel current under partial shading conditions. Based on (5), each PV panel has a voltage given by the following equation

$$
v_{p v(l)}=\frac{N_{s}}{k_{o}} \ln \left(\frac{I_{p h(l)}+I_{s a t}-i_{p v(l)}}{I_{s a t}}\right), \quad l=1,2, \ldots L,
$$

where $L$ is the sum of PV panels, $i_{p v(l)}$ and $v_{p v(l)}$ are the output current and voltage of the $l^{\text {th }} \mathrm{PV}$ panel; $i_{p v(l)}$ depends on the load, and $I_{p h(l)}$ is affected by the solar irradiation intensity. Figure 4 illustrates the case of uniform solar radiation on two PV panels with the same intensity of $86 \mathrm{~mW} / \mathrm{cm}^{2}$ and the case of non-uniform solar radiation with intensities of $86 \mathrm{~mW} / \mathrm{cm}^{2}$ and $57 \mathrm{~mW} / \mathrm{cm}^{2}$, respectively. The simulation result shows that only one peak exists in the uniform solar illuminance case $(286 \mathrm{~W})$ and two peaks occur in the non-uniform solar illuminance case, which are $202.4 \mathrm{~W}$ (i.e., global maximum) and $143 \mathrm{~W}$ (i.e., local maximum). When a PV system has many PV panels under partial shading effects, multiple power peaks will occur on the $\mathrm{P}-\mathrm{V}$ curve. When many power peaks occur, the global search for MPP is faulty by traditional methods, and the low energy conversion efficiency of PV systems is obtained. Therefore, an efficient MPP searching method should overcome local traps, respond quickly to rapidly changing weather conditions, and improve the efficiency of PV energy conversion.

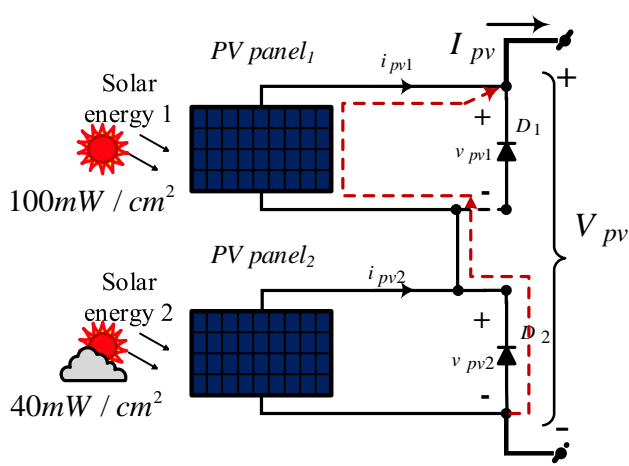

Fig. 3. Model of an actual PV system in two serial PV panels.

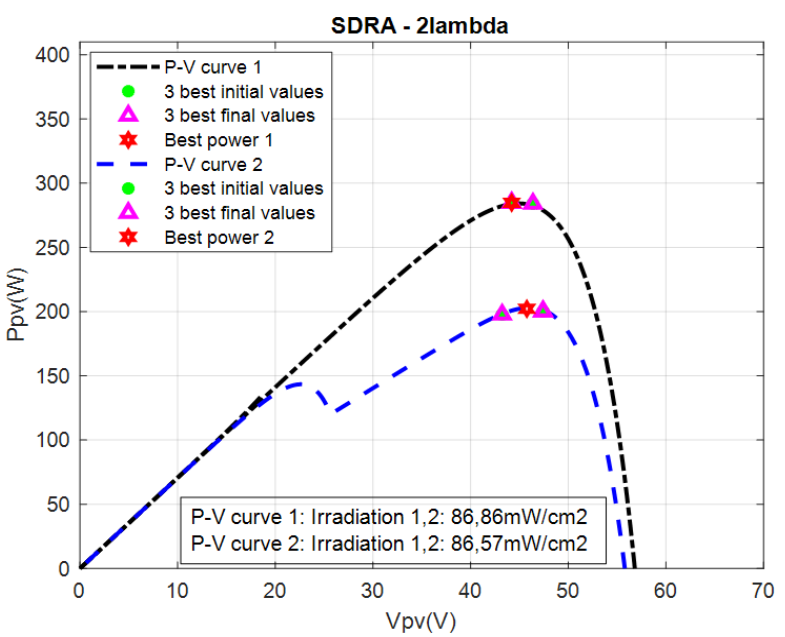

Fig. 4. Characteristic P-V curves under uniform solar irradiation and partial shading cases.

\section{DC-DC Boost Converter}

A typical boost converter consists of an electronic switch, an inductor, a diode, and a capacitor to store energy [24]. The boost converter is used to boost the input voltage to provide a higher output voltage and to coordinate 
impedance matching between the source and load by varying the duty ratio $\left(d_{r}\right)$. Each duty ratio value will control the electronic switch for the boost converter operation. The MPP tracking method will measure the PV current and PV voltage of the system and calculate the corresponding power value. Based on the proposed method, an optimal duty ratio value is found which is satisfied (8)

$$
d_{r}=1-\sqrt{Z_{p v} / Z_{\text {Load }}}
$$

where $Z_{\text {Load }}$ is the impedance seen from the output side of the boost converter and $Z_{p v}$ is the voltage quotient divided by the current of the PV array and depends on the intensity of solar irradiation on the PV panels.

\section{NOVEL ALGORITHM-BASED MPPT CONTROL FOR PV ENERGY SYSTEMS}

\section{A. Characteristic of a Stand-alone PV Energy System}

Solar illuminance intensity and environmental temperature are two main elements affecting the energy conversion performance of the PV system. Since conventional methods do not accommodate these changes, the power of the PV system is reduced, resulting in low energy conversion efficiency. Therefore, in this paper, an optimal algorithm to achieve global maximum power and an efficient energy conversion system were proposed in all situations. The stand-alone PV power conversion system consists of several PV panels in a serial configuration, a DC-DC boost converter with the corresponding power controller, and a DC load as illustrated in Fig. 1. This paper will propose the MPP tracking method to quickly and efficiently detect and compensate for the partial shading effect.

\section{B. SDRA Method for MPP Tracking under Partial Shading Effects}

Partial shading is the cause of the power loss of the PV system, while solutions are trapped in local MPPs. When partial shading occurs, most of the traditional methods have failed to find the global MPP. This paper proposes a new solution that exhibits the advantages of simplicity, efficiency, and low cost compared to other methods. The idea to constitute this algorithm is inspired by observing a short-distance running race in athletics to solve the problem of finding the global MPP under partial shading effects. This competition is organized into 3 rounds: qualifiers, quarter-finals, and finals. Depending on the size of the competition, the qualifying round will have more or less groups, each group usually has 6-12 runners. The runners are numbered and arranged on the starting line. After the end of the qualifying round, the runners exhibited the best time will be selected for the quarter-finals. The quarter-final is also divided into subgroups. The ranking process is still ongoing in this round. After the end of the quarter-finals, 3 to 7 runners with the highest rankings will be chosen to participate in the final round. The winner is the best runner in this final round. The goal of this algorithm is to find the winner in the fastest time, i.e., the global MPP can be found as quickly as possible. Based on this competition, the proposed algorithm is divided into 3 phases.

Inspired by the above short-distance running competition, a short-distance running algorithm (SDRA) is built and applied to find the global MPP of the PV power system. The SDRA method is very simple. Initially, the SDRA method proceeded to divide the individual area to avoid falling into local traps. The runners are numbered and divide the area as mentioned above. This dividing process is expressed by (9) as follows

$$
R_{\left(n, g_{1}\right)}=\left[\left(R_{\min }+(n-1) \times \Delta R\right) \quad\left(R_{\min }+n \times \Delta R\right)\right],
$$

where $\quad \Delta R=\left(R_{\max }-R_{\min }\right) / N, \quad R_{\min }=1000 * D_{\min }$, $R_{\max }=1000^{*} D_{\max }$, and $D_{\min }, D_{\max }$ are the lowest and highest thresholds of the duty ratio. The positions used in the proposed method are moved flexibly in its area. The runner will have a random position in the predetermined range as shown in (9). This position represents the duty ratio to control the DC-DC boost converter of the PV system. This is a key advantage of the SDRA method to search the global MPP with high accuracy and efficiency

$$
d_{r\left(n, g_{1}\right)}^{k}=\operatorname{randi}\left(R_{\left(n, g_{1}\right)}\right) / 1000,
$$

where $n=1,2 \ldots N$, with $N$ is the sum of runners, $g_{1}=1,2, \ldots G_{1}$, with $G_{1}$ is the total number of qualifying groups, and $k=1,2, \ldots K$, with $K$ is the number of displacements. Each duty ratio value will control the DCDC boost converter for a certain time to measure the PV voltage and PV current values of the PV array. After the end of the qualifying round, the duty ratios that achieved the best power corresponding to the fastest time will be selected for the quarter-finals. After eliminating positions that had bad records, the number of remaining runners will decrease, and the operating region will gradually narrow. The selected runners have a higher chance of ranking than other positions; this is a smart implementation to reduce the number of samples as well as the MPP searching time, while the achievement to obtain the global MPP is still not affected. Depending on the size of the competition, the number of runners in each group in the quarter-finals may be different compared to the qualifiers. In this phase, each position will be updated twice corresponding to the right and left neighboring positions to find the best value if available $(k=1,2)$. This is a new idea to determine once again the best position in the search region. The equation for this process is expressed as follows

$$
d_{r\left(m, g_{2}\right)}^{k+1}=d_{r\left(m, g_{2}\right)}^{k}+(-1)^{k} * k * \operatorname{randi}(\Delta R) /(1000 * 2),
$$

where $m=1,2 \ldots M$, with $M$ is the sum of runners in a quarter-final group and $g_{2}=1,2, \ldots G_{2}$, with $G_{2}$ is the total number of quarter-final groups. Similarly, each new value of the duty ratio results in a corresponding power value $P\left(d_{r\left(m, g_{2}\right)}^{k}\right)$. After the end of the quarter-finals, some of the best places will be selected to participate in the final round. 
Usually, the final round has $3 \sim 7$ runners. In this final round, the algorithm has a breakthrough in updating the new position, as well as the binding conditions to complete the competition. Based on actual observations, runners tend to move towards the leader to reduce air resistance. The leader also moves back and forth around the current position to find the most optimal position. Each result to a new position is measured to determine the new optimal position. This approach not only accurately searches for the MPP, but also speeds up the convergence of the proposed algorithm. The movement of the runner is represented by the following equation

$$
d_{r(e)}^{k+1}=d_{r(e)}^{k}+\left\{\begin{array}{l}
+(\Delta d) / 2, \text { if } d_{r(e)}^{k}<d_{r(b e s t)} \\
-(\Delta d) / 2, \text { if } d_{r(e)}^{k}>d_{r(b e s t)} \\
r a n d i(1000 * \Delta d) /(1000 * 2), \text { otherwise }
\end{array}\right.
$$

where $e=1,2, \ldots E$, with $E$ is the number of the final runners; $\Delta d=\left|d_{r(\text { best })}-d_{r(\text { worst })}\right|$ is defined as the new operating region. This value depends on the position of the fastest runner $\left(d_{r(\text { best })}\right)$ and slowest runner $\left(d_{r(\text { worst })}\right)$ among the remaining runners who participated in the final round. The distance between these two positions is called the "operation area". The competition will end when the condition of (13) is satisfied, i.e., all remaining runners will appear in the global power region. And the winner is the best capacity position corresponding to $d_{r(b e s t)}$

$$
\left|d_{r(e)}^{k+1}-d_{r(b e s t)}\right| \leq \eta^{*} \Delta R / 1000
$$

where $\eta$ is an adjustment factor; this value depends on the number of runners in a group $(N)$ and $\eta<1$. The process to implement the proposed method is shown in Fig. 5.

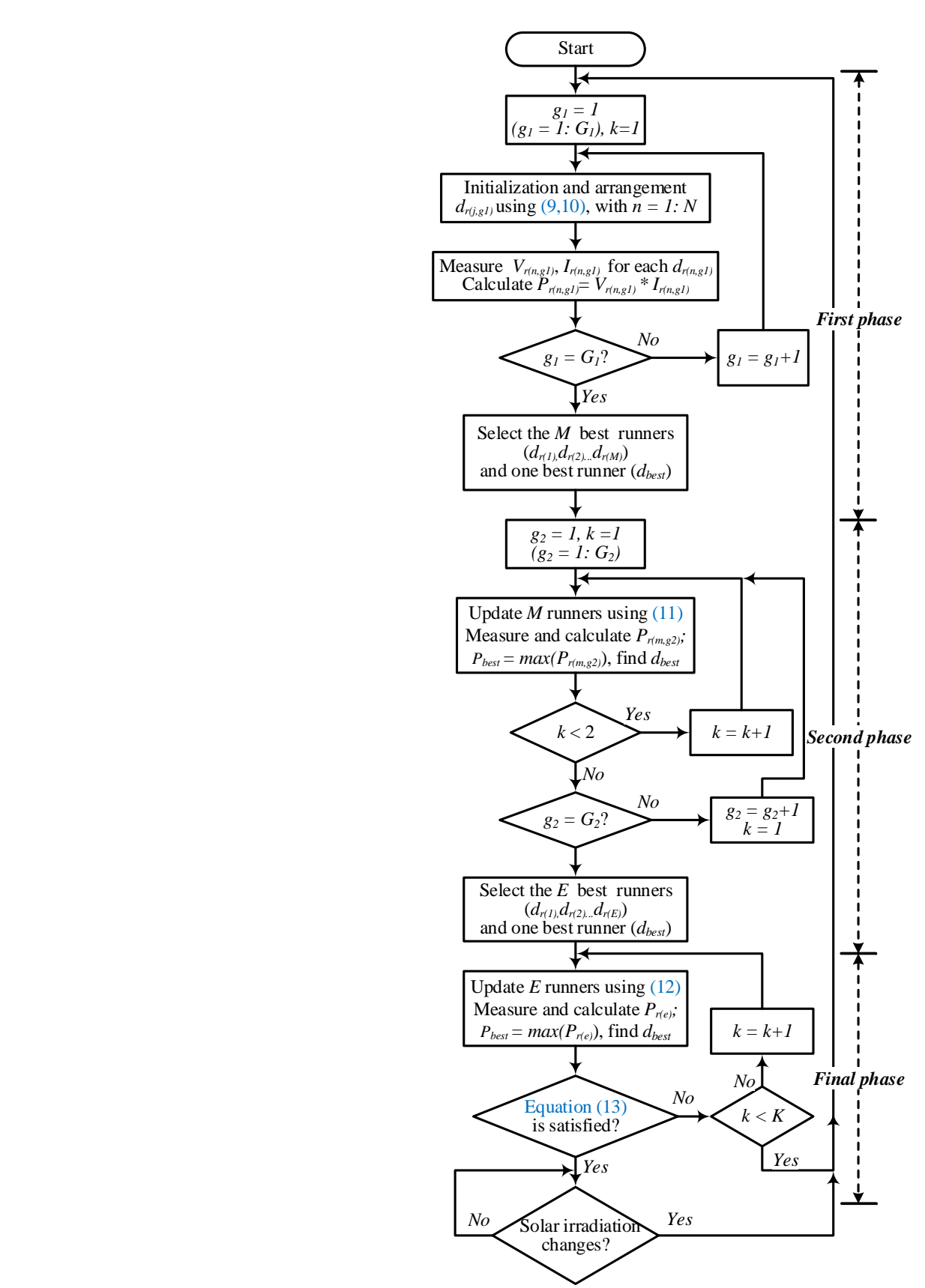

Fig. 5. Flowchart of the SDRA-based MPP tracking method. 
Remark: Compared to other methods, the proposed SDRA method only uses individuals with the best capacity to join the next search process, which reduces the number of samples and the search time. In contrast, traditional methods still maintain the original individuals. On the other hand, the new position update of the SDRA method tends to move to the best position, which being different from the traditional methods. Finally, the proposed MPP search will finish when only a few of the best individuals converge in a specified range. As a result, the convergence time of SDRA is less than other methods, such as improved PSO [15], [25] ACO [12], enhanced GWO [17], bat algorithm (BA) [19], and hybrid method [26].

\section{Simulation Results}

A stand-alone PV power system is deployed to verify the effectiveness of the proposed approach, as shown in Fig. 1. The MATLAB program is developed to search for global MPP via the SDRA method. The proposed SDRA MPPT method is compared with conventional PSO and GWA methods. The simulation process will be performed for two systems (i.e., two serial PV panels and three serial PV panels) in terms of many different solar situations. The operation time for each duty ratio is 12.5 milliseconds, corresponding to 250 sampling cycles. The boost converter has the following parameters: the inductor $L=300 \mathrm{e}-5 \mathrm{H}$, the input capacitor $C_{i n}=300 \mathrm{e}-6 F$, the output capacitor $C_{\text {out }}=470 \mathrm{e}-6 \mathrm{~F}$, the resistant load $R_{\text {load }}=44 \Omega$, the frequency to control the boost converter is $20 \mathrm{kHz}$. The typical specifications of each PV panel are shown in Table II. The initial parameters of the proposed method were set as follows: $G_{1}=3 ; N=9, G_{2}=2, M=4, E=3$, and $K=$ 6. To verify the advantages of the proposed SDRA, the conventional PSO, GWA methods are chosen to consider and evaluate the efficiency in terms of the global MPP searching, as well as their convergence time.

\section{A. The Case of Two Serial PV Panels}

Two different scenarios are considered, as established in Fig. 4, for the system with two serial PV panels, resulting in two P-V curves marked as P-V curve 1 and $\mathrm{P}-\mathrm{V}$ curve 2. This strategy will be carried out to evaluate and compare the effectiveness of the SDRA method and two conventional PSO, GWA methods under uniform solar illuminance and partial shading influences. In this case, the illuminance levels of both PV panels are set at the same value of $86 \mathrm{~mW} / \mathrm{cm}^{2}$ for uniform solar irradiation initially, and then one panel is partially shaded with $57 \mathrm{mW/ \textrm {cm } ^ { 2 }}$ after 3 seconds. The temperature of the panels is set at $25^{\circ} \mathrm{C}$. Scenario 1 is simulated to exist for the first three seconds, and the second scenario appears for the next three seconds. The P-V curve characteristics exhibit two peaks with one global maximum and one local maximum for the partial shading scenario 2 as shown in Fig. 4. The MPP tracking results in Figs. 6-8 show that the SDRA-based method and conventional PSO, GWA methods can obtain the global MPP, which is about $286 \mathrm{~W}$ in uniform solar irradiation and approximately $202.4 \mathrm{~W}$ in partial shading condition. The conventional PSO, GWA methods are capable of reaching the global MPP but take 0.69, 0.76 seconds for scenario 1 and $0.7,0.7$ seconds for scenario 2 for convergence, respectively. Furthermore, conventional PSO, GWA methods generate oscillations in PV output power for a longer duration compared to the proposed SDRA method, which only reaches the global MPP with 0.55 seconds for scenario 1 and 0.56 seconds for scenario 2 .

\section{B. Case 2 of Three PV Panel Configuration in Series}

To evaluate and confirm the efficiency and accuracy of the SDRA-based MPP tracking method under rapidly changing solar irradiance conditions, two partial shading scenarios are considered for the PV system with three serial PV panels. The first scenario is simulated for the first three seconds with solar irradiances of $100 \mathrm{~mW} / \mathrm{cm}^{2}, 70 \mathrm{~mW} / \mathrm{cm}^{2}$, and $40 \mathrm{~mW} / \mathrm{cm}^{2}$ respectively, and with solar irradiances of $100 \mathrm{~mW} / \mathrm{cm}^{2}, 40 \mathrm{~mW} / \mathrm{cm}^{2}$, and $30 \mathrm{~mW} / \mathrm{cm}^{2}$ for the second scenario, which takes place in the next three seconds. The electrical characteristics of this PV configuration subjected to partial shading scenarios 1, 2 are shown in Fig. 9. From these two scenarios, it is noticed that the SDRA method can efficiently track global MPP for all dynamically changing shading scenarios. The algorithm restarts the MPP search by sensing the change of PV power during different partial shading scenarios. Moreover, a comparison between the SDRA method and conventional PSO, GWA methods is carried out under partial shading effects. The MPP search trajectories of the GWA, PSO, and proposed SDRA methods are shown in Figs. 10-12. All three methods achieve global MPPs of $296.5 \mathrm{~W}$ and $199.4 \mathrm{~W}$ for partial shading scenarios 1 and 2 . The tracking time for the conventional GWA and PSO is $0.91,0.79$ seconds for partial shading scenario 1 and $0.81,0.70$ seconds for partial shading scenario 2, respectively. Similarly, the global MPP tracking time using the proposed method 1 is 0.53 seconds and 0.54 seconds for partial shading scenarios 1 and 2 , respectively. This result once again illustrates the superiority of the SDRA method with faster convergence to global MPP and reduced duration of PV output power oscillations (Table III).
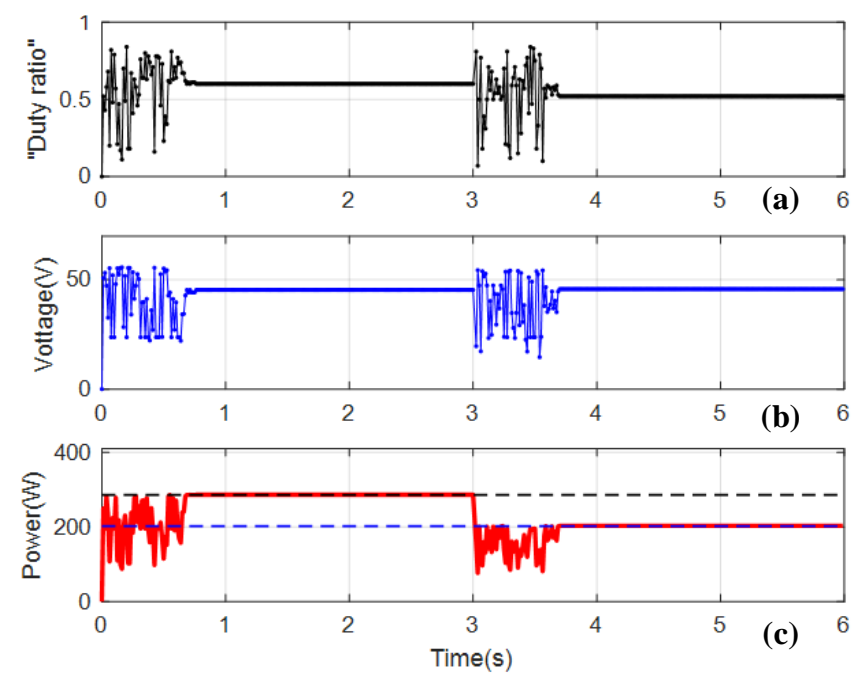

Fig. 6. Tracking trajectories of the GWA method for two serial PV panels: (a) duty ratio, (b) voltage, (c) power. 

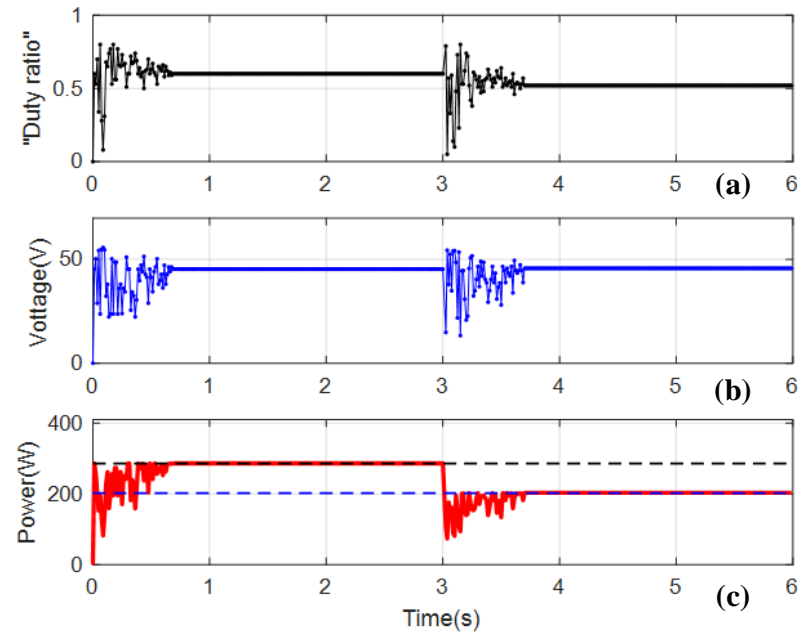

Fig. 7. Tracking trajectories of the PSO method for two serial PV panels: (a) duty ratio, (b) voltage, (c) power.
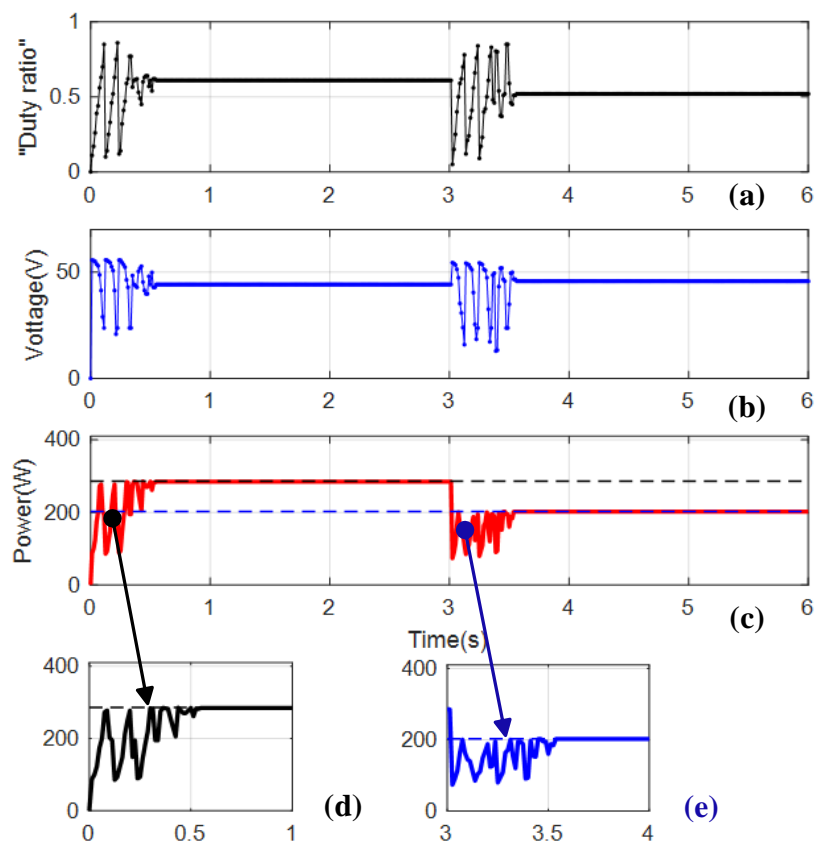

Fig. 8. Tracking trajectories of the proposed method of two serial PV panels: (a) duty ratio, (b) voltage, (c) power; (d) and (e) are the magnified results of the power for scenarios 1,2 , respectively.

SDRA

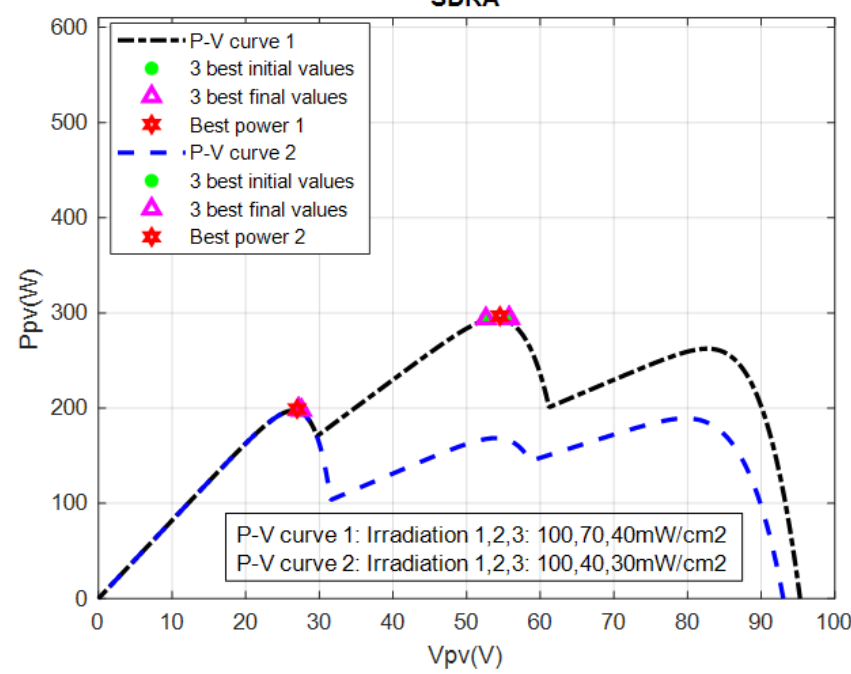

Fig. 9. P-V characteristics of three serial PV panels for partial shading scenarios.
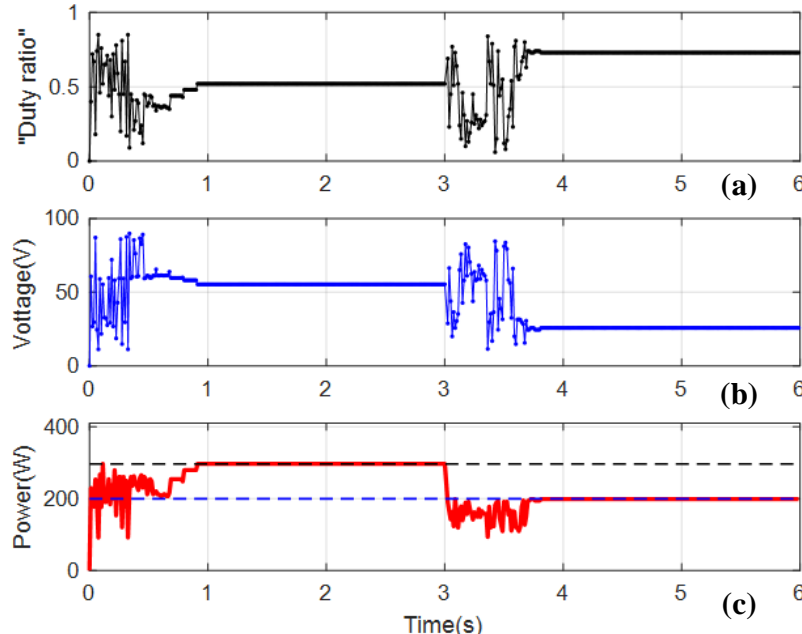

Fig. 10. Tracking trajectories of the GWA method for three serial PV panels under partial shading conditions: (a) duty ratio, (b) voltage, (c) power.
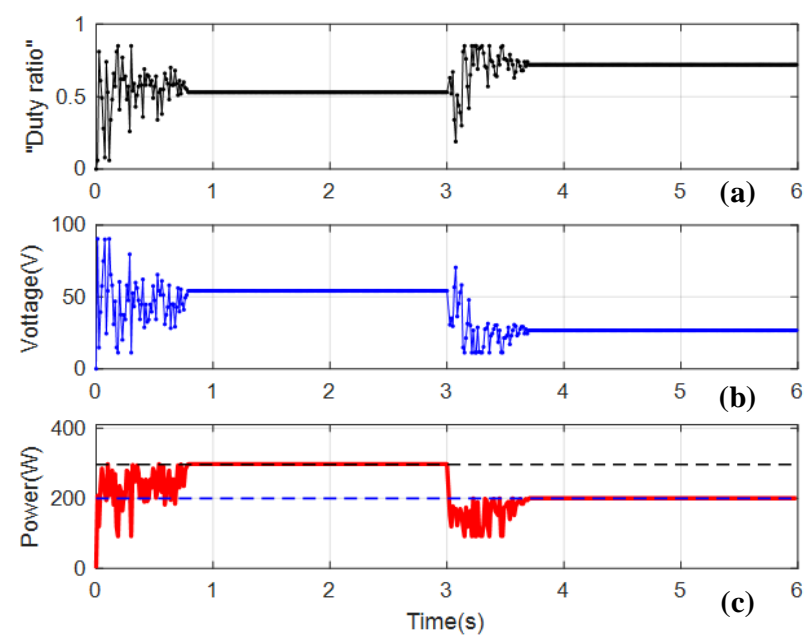

Fig. 11. Tracking trajectories of the PSO method for three serial PV panels under partial shading conditions: (a) duty ratio, (b) voltage, (c) power.
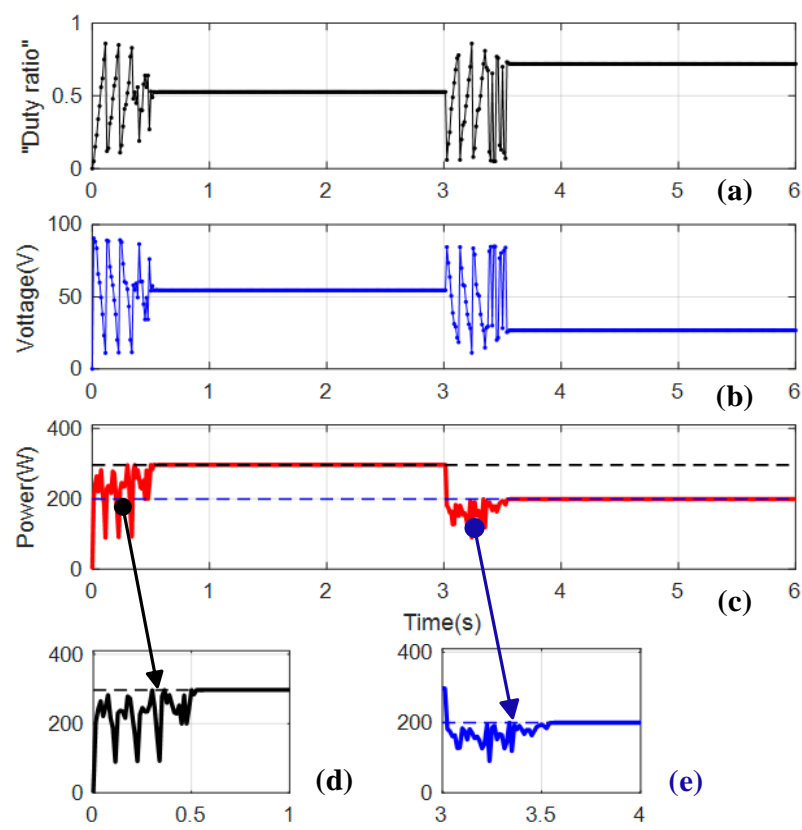

Fig. 12. Tracking trajectories of the proposed method for three serial PV panels under partial shading conditions: (a) duty ratio, (b) voltage, (c) power; (d) and (e) are the magnified results of the power for scenarios 1, 2, respectively. 
TABLE II. THE SPECIFICATIONS OF THE PV PANEL.

\begin{tabular}{|c|c|}
\hline Description & Value \\
\hline Maximum output power $\left(P_{\max }\right)$ & $200 \mathrm{~W} \pm 10 \%$ \\
\hline Maximum operating current $\left(I_{\max }\right)$ & $7.61 \mathrm{~A}$ \\
\hline Maximum operating voltage $\left(V_{\max }\right)$ & $26.3 \mathrm{~V}$ \\
\hline PV cell in parallel $\left(N_{p}\right)$ & $1 \mathrm{pcs}$ \\
\hline Open circuit voltage $\left(V_{o c}\right)$ & $32.9 \mathrm{~V}$ \\
\hline PV cell in series $\left(N_{s}\right)$ & $54 \mathrm{pcs}$ \\
\hline Short circuit current $\left(I_{s c}\right)$ & $8.21 \mathrm{~A}$ \\
\hline P-N junction parameter $\left(B_{s}\right)$ & 1.8 \\
\hline
\end{tabular}

TABLE III. MPPT RESULTS WITH DIFFERENT SCENARIOS.

\begin{tabular}{|c|c|c|c|c|c|}
\hline \multirow[b]{2}{*}{ Case } & \multirow{2}{*}{$\begin{array}{c}\text { Irradiance } \\
\text { intensity } \\
\left(\boldsymbol{m V} / \mathrm{cm}^{2}\right)\end{array}$} & \multirow{2}{*}{$\begin{array}{c}\begin{array}{c}\text { Ideal } \\
\text { power at } \\
\text { global }\end{array} \\
\text { MPP } \\
(W)\end{array}$} & PSO & GWA & SDRA \\
\hline & & & $\begin{array}{l}\text { Time } \\
\text { (s) }\end{array}$ & $\begin{array}{c}\text { Time } \\
(\mathbf{s})\end{array}$ & $\begin{array}{c}\text { Time } \\
\text { (s) }\end{array}$ \\
\hline \multirow{2}{*}{$\begin{array}{c}1 \\
\text { (2 panels) }\end{array}$} & {$[86,86]$} & 286.0 & 0.69 & 0.76 & 0.57 \\
\hline & {$[86,57]$} & 202.4 & 0.70 & 0.70 & 0.56 \\
\hline \multirow{2}{*}{$\begin{array}{c}2 \\
\text { (3 panels) }\end{array}$} & $\begin{array}{c}{[100,70,} \\
40]\end{array}$ & 296.5 & 0.79 & 0.91 & 0.53 \\
\hline & $\begin{array}{c}{[100,94,} \\
30]\end{array}$ & 199.4 & 0.70 & 0.81 & 0.54 \\
\hline
\end{tabular}

\section{V.EXPERIMENTAL RESULTS}

\section{A. Circuit Design for MPP Tracking Strategy of Stand- alone PV Energy Systems}

To further demonstrate the efficiency and feasibility of the SDRA method, the experiments are performed in a real environment at around $31{ }^{\circ} \mathrm{C}$ to $33{ }^{\circ} \mathrm{C}$ of ambient temperature. The experimental model is built based on the configuration shown in Fig. 1, where the two PV panels are connected in series and each panel is connected in shunt with a bypass diode (Fig. 3). The basic specifications of the PV power panel and the initial parameters of the methods are the same as those of the simulation. The experiment with an ARDUINO Mega2560 board-controlled DC/DC boost converter is performed to evaluate the SDRA MPP search method. This ARDUINO Mega 2560 board exhibits simple structure, high clock speed $(16 \mathrm{MHz})$, and easy to use I/O interface. The Mega 2560 microcontroller has 16 analog inputs, each of which provides 10 bits of resolution, and has 54 digital I/O pins (of which 14 pins provide pulse width modulation (PWM) output) used for signal measurement and control. The basic parameters of the boost converter are the capacitor $C=330 \mu F / 450 \mathrm{~V}$, the inductor $L=1.5 \mathrm{mH}$, the fast switching diode $D=M B R 30200 P T$, the MOSFET $Q=I R F P 250 N$, and the resistant load $R_{\text {load }}=44 \Omega$. Each duty ratio value operates for 30 milliseconds so that the methods record the PV current and PV voltage values of the power system through the current sensor and the voltage divider by the resistors $R_{1}$ and $R_{2}$. A simple designed circuit for the stand-alone PV system is employed to implement the proposed method and other methods as depicted in Fig. 13. The experimental model is displayed in Fig. 14.

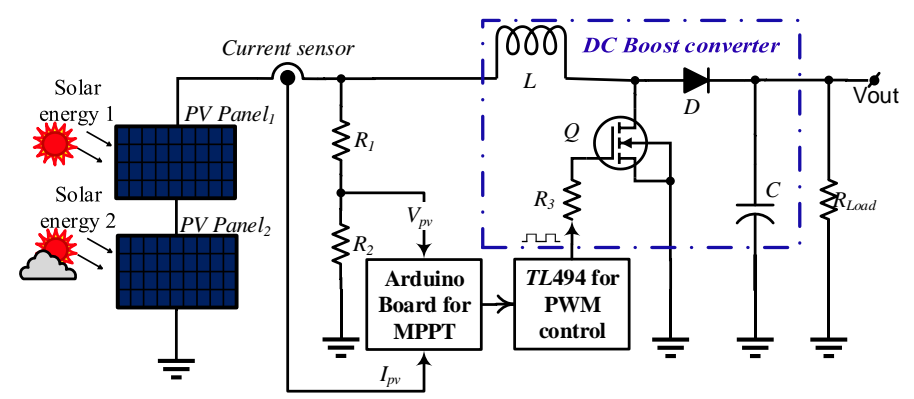

Fig 13. Experimental PV system architecture.

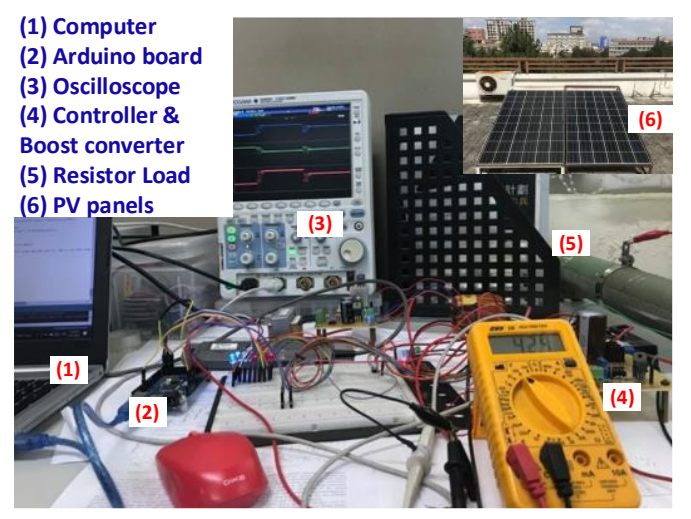

Fig. 14. Practical experimental model for a stand-alone PV system.

\section{B. Experimental Results and Discussion}

Under normal weather conditions, the measured solar radiation intensity on the two PV panels is the same value of $86 \mathrm{~mW} / \mathrm{cm}^{2}$. After applying the methods, the global MPP value during the uniform condition is obtained at about $287 \mathrm{~W}$ for all three methods. The proposed SDRA method only takes 1.2 seconds to obtain the global MPP. In contrast, 1.6 and 1.4 seconds are taken to achieve the global MPP by conventional GWA and PSO methods, respectively. When partial shading occurs in one PV panel after about 8 seconds, the measured solar radiation intensity on two PV panels are $86 \mathrm{~mW} / \mathrm{cm}^{2}$ and $57 \mathrm{~mW} / \mathrm{cm}^{2}$ for the PV panels 1 and 2, sequentially. The MPP tracking result of the three methods also reached the global MPP with a value of about 202.4 W. The MPP searching times of the SDRA method and the conventional GWA, PSO are 1.2 and 1.7, 1.5 seconds, respectively. The characteristics of the P-V curves in these situations are depicted in Fig. 4. The detailed results of the three methods are shown in Figs. 15-17 of the experiment implementations corresponding to the simulation work (Figs. 6-8).

The results shown in the above figures proved that the SDRA method is capable of tracking the global MPP during partial shading conditions, as well as uniform solar irradiation intensity. Although the GWA and PSO methods can search the global MPP, the new SDRA method exhibits less power and voltage fluctuations. The effectiveness and accuracy of the new SDRA method are also demonstrated by the faster convergence time, even if the number of initial samples of the proposed method is greater than 3 times (27 
versus 9). The accuracy of the proposed method increases when the initial number of $G_{1}, G_{2}$ groups, as well as the number of members in each group, increase. However, the execution time will increase, so that a high-speed microcontroller should be replaced.

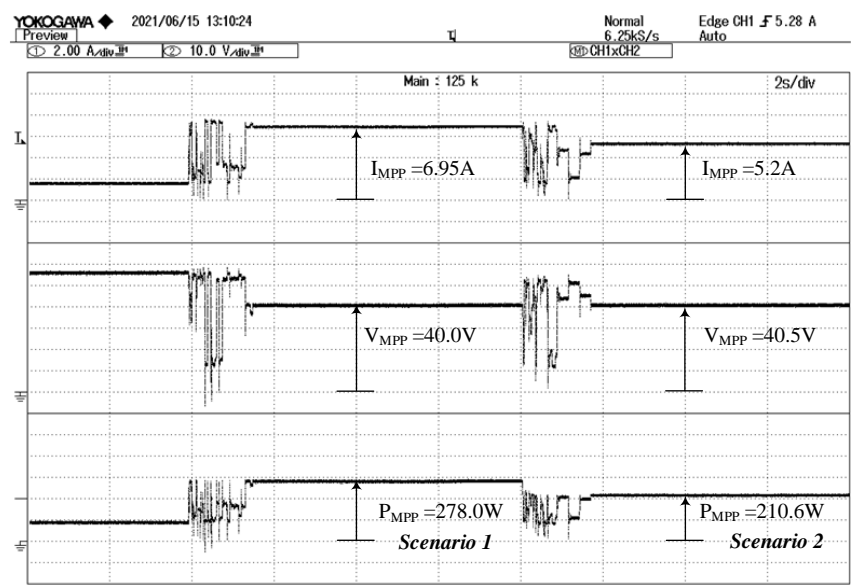

Fig. 15. Experimental tracking trajectories of the GWA method for two serial PV panels (from top to bottom: current, voltage, power).

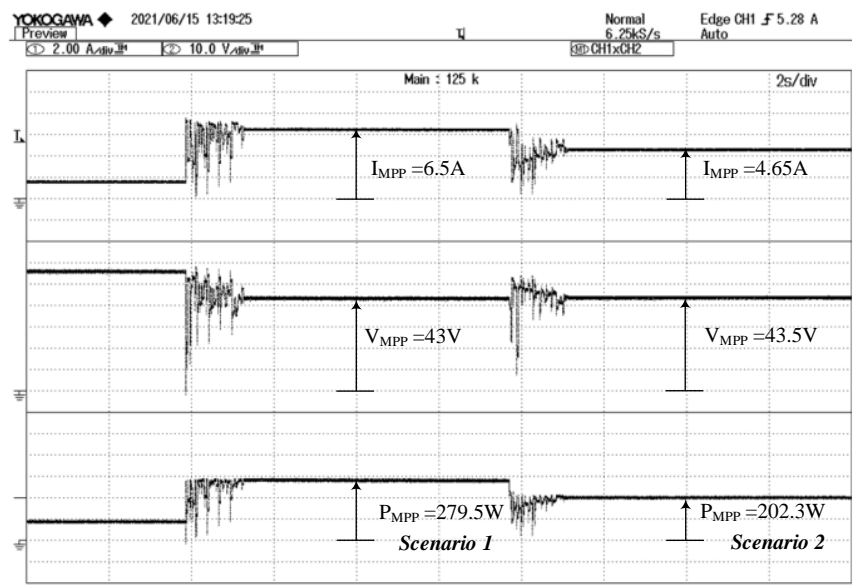

Fig. 16. Experimental tracking trajectories of the PSO method for two serial PV panels (from top to bottom: current, voltage, power).

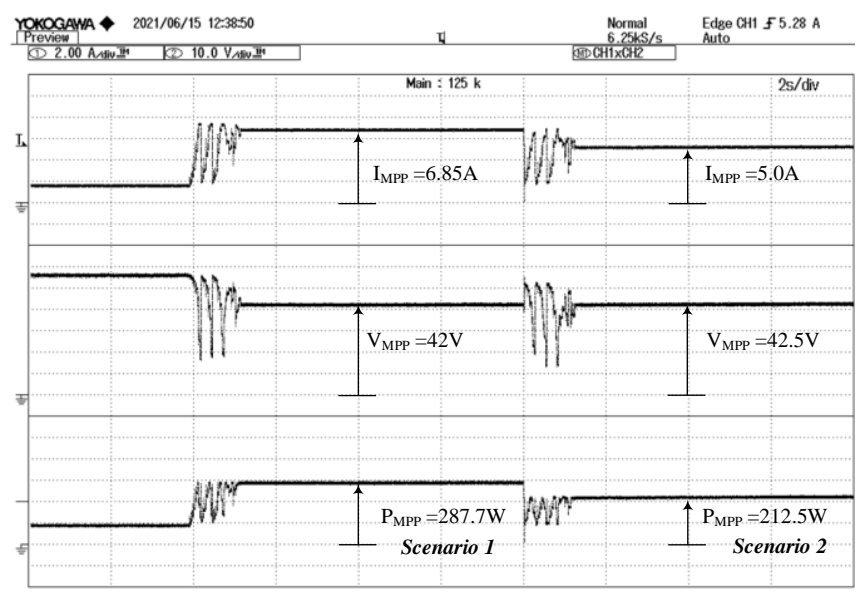

Fig. 17. Experimental tracking trajectories of the proposed method for two serial PV panels (from top to bottom: current, voltage, power).

\section{CONCLUSIONS}

The efficacy of the SDRA-based MPP tracking strategy is exhibited with the key advantages of fast convergence time, high accuracy, and easy implementation compared to traditional methods. The proposed SDRA method is highly effective because it responds positively to rapid and sudden changes in weather conditions. These merits are based on new ideas in the division of the search area at a first stage. This process repeated with new random positions will increase the accuracy of the solution in the global MPP search. Moreover, only the best positions are selected to update the new positions, giving the opportunity to find the MPP more quickly with less execution time. It is worth mentioning that the proposed method is easy to implement and has high efficiency to practical application.

\section{CONFLICTS OF INTEREST}

The authors declare that they have no conflicts of interest.

\section{REFERENCES}

[1] G. Li, Y. Chen, Y. Yu, R. Tang, and A. Mawire, "Performance and design optimization of single-axis multi-position sun-tracking PV panels", Journal of Renewable Sustainable Energy, vol. 11, no. 6, p 063701, 2019. DOI: 10.1063/1.5115976.

[2] B. Benlahbib, N. Bouarroudj, S. Mekhilef, T. Abdelkrim, A Lakhdari, and F. Bouchafaa, "A Fuzzy logic controller based on maximum power point tracking algorithm for partially shaded PV array-experimental validation", Elektronika ir Elektrotechnika, vol 24, no. 4, pp. 38-44, 2018. DOI: 10.5755/j01.eie.24.4.21476.

[3] K. Saidi, M. Maamoun, and M'h. Bounekhla, "A new high performance variable step size perturb-and-observe MPPT algorithm for photovoltaic system", International Journal of Power Electronics Drive System, vol. 10, no. 3, pp. 1662-1674, 2019. DOI: 10.11591/ijpeds.v10.i3.pp1662-1674.

[4] N. Kumar, I. Hussain, B. Singh, and B. K. Panigrahi, "Self-adaptive incremental conductance algorithm for swift and ripple-free maximum power harvesting from PV array", IEEE Transactions on Industrial Informatics, vol. 14, no. 5, pp. 2031-2041, 2018. DOI 10.1109/TII.2017.2765083.

[5] H.-D. Liu, C.-H. Lin, K.-J. Pai, and Y.-L. Lin, “A novel photovoltaic system control strategies for improving hill climbing algorithm efficiencies in consideration of radian and load effect", Energy Conversion and Management, vol. 165, pp. 815-826, 2018. DOI: 10.1016/j.enconman.2018.03.081.

[6] S. Motahhir, A. Chalh, A. El Ghzizal, and A. Derouich, "Development of a low-cost PV system using an improved INC algorithm and a PV panel Proteus model", Journal of Cleaner Production, vol. 204, pp. 355-365, 2018. DOI: 10.1016/j.jclepro.2018.08.246.

[7] A. M. O. Anwer, F. A. Omar, H. Bakir, and A. A. Kulaksiz, "Sensorless control of a PMSM drive using EKF for wide speed range supplied by MPPT based solar PV system", Elektronika ir Elektrotechnika, vol. 26, no. 1, pp. 32-39, 2020. DOI: 10.5755/j01.eie.26.1.25308.

[8] M. Kamran, M. Mudassar, M. R. Fazal, M. U. Asghar, M. Bilal, and R. Asghar, "Implementation of improved Perturb \& Observe MPPT technique with confined search space for standalone photovoltaic system", Journal of King Saud University - Engineering Sciences, vol 32, no. 7, pp. 432-441, 2020. DOI: 10.1016/j.jksues.2018.04.006.

[9] M. Kermadi and E. M. Berkouk, "Artificial intelligence-based maximum power point tracking controllers for Photovoltaic systems: Comparative study", Renewable and Sustainable Energy Reviews, vol. 69, pp. 369-386, 2017. DOI: 10.1016/j.rser.2016.11.125.

[10] S. Hadji, J.-P. Gaubert, and F. Krim, "Real-time genetic algorithmsbased MPPT: Study and comparison (theoretical an experimental) with conventional methods", Energies, vol. 11, no. 2, p. 459, 2018. DOI: $10.3390 /$ en 11020459.

[11] M. A. Mohamed, A. A. Zaki Diab, and H. Rezk, "Partial shading mitigation of PV systems via different meta-heuristic techniques", Renewable Energy, vol. 130, pp. 1159-1175, 2019. DOI: 10.1016/j.renene.2018.08.077.

[12] S. Titri, C. Larbes, K. Y. Toumi, and K. Benatchba, "A new MPPT controller based on the Ant colony optimization algorithm for Photovoltaic systems under partial shading conditions", Applied Soft Computing, vol. 58, pp. 465-479, 2017. DOI 10.1016/j.asoc.2017.05.017.

[13] J. Farzaneh, R. Keypour, and M. A. Khanesar, "A new maximum power point tracking based on modified firefly algorithm for PV 
system under partial shading conditions", Technology and Economics of Smart Grids and Sustainable Energy, vol. 3, no. 1, art. no. 9, 2018. DOI: 10.1007/s40866-018-0048-7.

[14] R. Motamarri, N. Bhookya, and B. Chitti Babu, "Modified grey wolf optimization for global maximum power point tracking under partial shading conditions in photovoltaic system", International Journal of Circuit Theory and Applications, vol. 49, no. 7, pp. 1884-1901, 2021. DOI: $10.1002 / \mathrm{cta} .3018$

[15] K. Hu, S. Cao, W. Li, and F. Zhu, "An improved particle swarm optimization algorithm suitable for photovoltaic power tracking under partial shading conditions", IEEE Access, vol. 7, pp. 143217-143232, 2019. DOI: 10.1109/ACCESS.2019.2944964.

[16] S. Obukhov, A. Ibrahim, A. A. Zaki Diab, A. S. Al-Sumaiti, and R. Aboelsaud, "Optimal performance of dynamic particle swarm optimization based maximum power trackers for stand-alone PV system under partial shading conditions", IEEE Access, vol. 8, pp 20770-20785, 2020. DOI: 10.1109/ACCESS.2020.2966430.

[17] S. K. Cherukuri and S. R. Rayapudi, "Enhanced grey wolf optimizer based MPPT algorithm of PV system under partial shaded condition", International Journal of Renewable Energy Development, vol. 6, no. 3, pp. 203-212, 2017. DOI: 10.14710/ijred.6.3.203-212.

[18] R. Sridhar, S. Jeevananthan, S. S. Dash, and P. Vishnuram, “A new maximum power tracking in PV system during partially shaded conditions based on shuffled frog leap algorithm", Journal of Experimental \& Theoretical Artificial Intelligence, vol. 29, no. 3, pp. 481-493, 2017. DOI: 10.1080/0952813X.2016.1186750.

[19] A. M. Eltamaly, M. S. Al-Saud, and A. G. Abokhalil, "A novel bat algorithm strategy for maximum power point tracker of photovoltaic energy systems under dynamic partial shading", IEEE Access, vol. 8 , pp. 10048-10060, 2020. DOI: 10.1109/ACCESS.2020.2964759.
[20] J.-Y. Shi, F. Xue, Z.-J. Qin, W. Zhang, L.-T. Ling, and T. Yang, "Improved global maximum power point tracking for photovoltaic system via cuckoo search under partial shaded conditions", Journal of Power Electronics, vol. 16, no. 1, pp. 287-296, 2016. DOI: 10.6113/JPE.2016.16.1.287.

[21] C.-S. Chiu and S. Ngo, "Hybrid SFLA MPPT design for multi-module partial shading photovoltaic energy systems", International Journal of Electronics, 2022. DOI: 10.1080/00207217.2021.2025443.

[22] M. Bahrami, R. Gavagsaz-Ghoachani, M. Zandi, M. Phattanasak, G. Maranzanaa, B. Nahid-Mobarakeh, S. Pierfederici, and F. MeibodyTabar, "Hybrid maximum power point tracking algorithm with improved dynamic performance", Renewable Energy, vol. 130, pp. 982-991, 2019. DOI: 10.1016/j.renene.2018.07.020.

[23] S. Borekci, E. Kandemir, and A. Kircay, "A simpler single-phase single-stage grid-connected PV system with maximum power point tracking controller", Elektronika ir Elektrotechnika, vol. 21, no. 4, pp. 44-49, 2015. DOI: 10.5755/j01.eee.21.4.12782.

[24] E. Irmak and N. Güler, "A model predictive control-based hybrid MPPT method for boost converters", International Journal of Electronics, vol. 107, no. 1, pp. 1-16, 2020. DOI: 10.1080/00207217.2019.1582715.

[25] A. Ibrahim, R. Aboelsaud, and S. Obukhov, "Improved particle swarm optimization for global maximum power point tracking of partially shaded PV array", Electrical Engineering, vol. 101, no. 2, pp. $443-$ 455, 2019. DOI: 10.1007/s00202-019-00794-w.

[26] Y.-P. Huang, X. Chen, and C.-E. Ye, "A hybrid maximum power point tracking approach for photovoltaic systems under partial shading conditions using a modified genetic algorithm and the firefly algorithm", International Journal of Photoenergy, vol. 2018, art. ID 7598653, 2018. DOI: 10.1155/2018/7598653

This article is an open access article distributed under the terms and conditions of the Creative Commons Attribution 4.0 (CC BY 4.0) license (http://creativecommons.org/licenses/by/4.0/) 